\title{
Receiving the Initial Down Syndrome Diagnosis: A Comparison of Prenatal and Postnatal Parent Group Experiences
}

\author{
Briana S. Nelson Goff, Nicole Springer, Laura Cline Foote, Courtney Frantz, Madison Peak, \\ Courtney Tracy, Taylor Veh, Gail E. Bentley, and Kayli A. Cross
}

\begin{abstract}
This study explored the preliminary experiences of parents upon learning of their child's diagnosis of Down syndrome. Qualitative data from a web-based, national survey were analyzed based on two groups: prenatal $(n=46)$ or postnatal $(n=115)$ diagnosis. Three primary categories emerged from the data analysis: prenatal screening/testing decisions by parents, the adjustment process for parents, and postdiagnosis resources and support for parents. Participants' rationale behind pursuing testing ranged from wanting to be better prepared to not pursuing testing because it was not a factor in continuing the pregnancy. Participant reactions to the diagnosis involved a range of intense preliminary emotions; participants described their extreme grief and loss experience at the initial news of the diagnosis, which also was ambiguous in nature and required differing timelines of adjustment. Finally, participants described experiences with medical professionals, information/ education, and faith/religion as resources and areas of support, although not all were described as positive in nature. Participants in both groups identified having negative experiences with medical professionals during the diagnosis process. The results indicated the importance of these early experiences for parents of children with Down syndrome and emphasize providing effective education, resources, and practical information from reliable sources.
\end{abstract}

Key Words: Down syndrome; parenting; prenatal diagnosis; postnatal diagnosis; qualitative research

Although there are nearly 1,000 genetic-chromosomal disorders, Down syndrome (DS) is the most common, occurring, on average, in 1 of every 690 live births (National Association for Down Syndrome [NADS], 2012). Most individuals with DS have mild to moderate mental and physical impairments and often face an assortment of health problems, including congenital heart defects, low muscle tone, vision and hearing problems, and thyroid conditions (NADS, 2012). Life expectancy, opportunities for education, employment and independence, and other positive outcomes for children with DS have expanded in the last few years (National Down Syndrome Congress [NDSC], 2012).

Historically, research on families with children who have a disability has been grounded within a deficit framework and explored the negative factors associated with disability as a life stressor. Cunningham (1996) researched families living with DS and has published one of the only longitudinal DS studies. The results indicated that the "overall impression of the families and children with Down syndrome is one of normality" (p. 93). The factors that influence the welfare of these families are similar to those that influence any child or family. The findings actually pointed to more positive effects of having a child with DS, rather than negative pathology being created because of the disability. The study also emphasized diversity among families with children with disabilities, leaving room for effective intervention strategies to be researched and formulated.

\section{Parental Coping and the Adjustment Process}

Parents of children with DS and other disabilities encounter a variety of challenges associated with raising their children (e.g., developmental, medical, educational) and with more frequency that most parents of typically developing children do not 
experience. Coping with their child's condition, understanding what developmental limitations exist, identifying and accessing necessary specialized care and medical services (e.g., occupational, physical, or speech therapy), locating community resources and support, and planning for the future are common demands described by parents of children with special needs (Flaherty \& Masters Glidden, 2000; Glidden, Billings, \& Jobe, 2006). Although there may be greater demands on family resources and higher stress levels when there is a member with a disability, stress levels can be lessened by perceived social support and enhanced family coping strategies (Asberg, Vogel, \& Bowers, 2007; Cunningham, 1996).

Almost every study prior to the 1980 s anticipated poor outcomes for families of children with DS (Hodapp, 2007). Recent research indicates that having a child with DS is more like other stressors that families face; however, relatively little is known about the specific family or parenting experiences in raising a child with DS (Hodapp, 2007). Families of children with DS reportedly have slightly better coping scores than families with other disorders, yet mostly there are large gaps in knowledge and understanding of the specific experiences of these families, particularly the various effects or benefits of having a family member with DS (Hodapp, 2007).

How a family responds to stress and manages available resources can be seen in the coping strategies they activate (Cunningham, 1996; McCubbin \& Thompson, 1991). Coping strategies include such areas as activation of social support networks, which include extended family, friends, and neighbors, and appraisal strategies such as problem solving, reframing, and meaning making (McCubbin \& Thompson, 1991). Bower, Chant, and Chatwin (1998) explored the role of hardiness in families living with DS. The results of their study pointed to the conclusion that there are more similarities rather than differences between families with and without a child with DS. Also, the study evidenced that having a child with a disability can actually provide families with a sense of hardiness and resilience, rather than having the opposite effect. Joosa and Berthelsen (2006) conducted a study on parenting a child with DS and identified the following categories from the mothers' responses: the impact of having a child with Down syndrome, family relationships, parenting expectations and practices, social support, formal services, and society and community accep- tance. The mothers' responses concerning their first reactions to having a child with DS were more negative and founded in shock and fear. However, as they raised their child, their attitudes seemed to shift to a more positive outlook as they realized the deeper meaning and satisfaction the child brought to their lives, along with their raised awareness of family and community support. Van Riper (2007) explored the family adaptation process with families raising a child with DS and discovered that family demands, family resources, and family problem-solving communication were key elements in adaptation.

Families who utilize positive coping strategies and demonstrate adjustment or resilience will better adapt to the stressors involved in raising a child with a disability (Cunningham, 1996; Joosa \& Berthelsen, 2007; King, Baxter, Rosenbaum, Zwaigenbaum, \& Bates, 2009; Twoy, Connolly, \& Novak, 2007). Family coping and adjustment factors may be particularly important in understanding outcomes for children with DS, and the positive potential outcomes and unique experiences for these families should be further explored (Cuskelly, Hauser-Cram, \& Van Riper, 2008; Joosa \& Berthelsen, 2007; Poehlmann, Clements, Abbeduto, \& Farsad, 2005; Van Hooste \& Maes, 2003). One area that needs further exploration is the experience of parents who receive their child's diagnosis during the prenatal or postnatal period. Current literature on this area of study will be described next.

\section{Prenatal and Postnatal Diagnosis Experiences}

Some researchers have explored how couples arrived at the choice to continue or terminate a pregnancy due to the results of their prenatal screening or diagnosis (Sandelowski \& Jones, 1996), while others have examined the coping processes for those who have chosen to continue the pregnancy based on case study analysis (Allen \& Mullhauser, 1995). Sandelowski and Barroso (2005) investigated the process of couples deciding to terminate following a prenatal diagnosis. The themes identified from their study were: the dilemma of choice and decision making, the paradox of chosen losses and lost choices for the parents, and the couples' management of stigmatization and cognitive dissonance based on the outcome of their decision. Other researchers have examined the role of the partner relationship in adjusting to a prenatal 
diagnosis (Humphreys, Cappelli, Aronovitch, Allanson, \& Hunter, 2008). Humphreys and colleagues investigated five relationship variables of women's adjustment following testing and counseling. The results indicated that the couple relationship can promote individual and marital adjustment during the prenatal diagnostic testing experience. However, this study only examined the women's adjustment related to partner involvement in genetic counseling and does not shed light on the ongoing adjustment process for the couple once the baby is born.

Fewer studies have explored the experience of receiving a postnatal diagnosis, although the majority of women find out about their baby's condition postnatally (Skotko, 2005). Skotko (2005) conducted one of the largest DS surveybased studies to date, which explored postnatal support for women. The research specifically addressed how the diagnosis was delivered by the physician as well as the overall nature of the diagnosis experience. Participants highlighted the fear and anxiety they experienced in addition to the less than positive interactions with the medical professionals who delivered the news, which was indicated by a majority of the sample. Key factors in women describing the birth of their child in a positive manner included if the physician gave positive information about DS and provided up-todate materials. Skotko and colleagues (Skotko, Capone, Kishnani, \& Down Syndrome Diagnosis Study Group, 2009; Skotko, Kishnani, Capone, \& Down Syndrome Diagnosis Study Group, 2009) identified a variety of recommendations for health care professionals to incorporate into the delivery of the diagnosis, whether it is delivered prior to or after the birth. This literature highlights the critical decisions and experiences of parents, but to date, no literature has provided a comparison between parents of their prenatal or postnatal diagnosis experiences. In addition, most research has been conducted with small, female-only samples.

\section{Purpose of the Current Study}

Using a nondeficit (Grant, Ramcharan, \& Flynn, 2007) and qualitative (Creswell, Hanson, Plano Clark, \& Morales, 2007; Patton, 2002) research model, the current study sought to explore the early experiences of parents of children with DS, specifically at the time of their child's initial diagnosis. Ultimately, we wanted to understand the experience of receiving the DS diagnosis, whether prenatal or postnatal. This study attempted to establish a clearer description of: the initial emotions and experiences; the adjustment process in light of the diagnosis; and the impact of the responses of resources and support from those around them, including family, friends and medical professionals, on their coping and adjustment. By exploring these early experiences of parents, the research also addressed similarities and differences between prenatal and postnatal groups, a comparison that is currently limited in the literature.

\section{Method}

\section{Procedure}

This study was part of a larger study that explored the experiences of parents in families with a child with Down syndrome (DS). All participants were asked to complete an online survey and, if interested, to include contact information for possible follow-up interviews. The survey included both quantitative measures and qualitative questions, including questions that addressed how participants coped with their child's DS diagnosis, their relationship as a couple, and their hope and satisfaction with life. In addition, qualitative questions asked more about their initial response to the diagnosis, their current attitude about the diagnosis, and other specific experiences they have had as a parent to a child with DS.

\section{Data Collection}

Participants in the larger study were recruited through several local and national DS groups, including the National Down Syndrome Congress (ndsccenter.org; research webpage and national newsletter), Down Syndrome Guild of Greater Kansas City (kcdsg.org; webpage and newsletter), Band of Angels (bandofangels.com), and the Council for Exceptional Children (cec.sped.org). In addition, the NDSC forwarded information to points of contact at each of the affiliate organizations nationwide, who then distributed the study information through their local membership listservs. The research procedure was approved by the Kansas State University and Texas Tech University Institutional Review Boards (IRB). Recruitment materials included information about the study and the survey weblink for interested participants to access and complete the survey online. Although the survey remained open for further data collection, at the time data analysis was conducted for the current study, participants from 22 states and one other country had completed the online survey. 


\section{Qualitative Data Analysis}

For the current study, a qualitative comparative analysis was utilized to conduct the data analysis (Patton, 2002). The goal was to analyze the reported experiences of the participants regarding their child's DS diagnosis. For the purpose of this study, the data analysis addressed the following primary research question (including four prompting questions) from the online survey: Describe the experience when you first learned of your child's diagnosis with Down syndrome: What were your initial reactions/emotions/thoughts? What was the process in adjusting to your child's diagnosis? What was your experience with prenatal testing? Would you make the same decision again? Participants were divided into prenatal and postnatal groups based on when they learned of their child's diagnosis. For the current study, 161 total participants were identified based on completion of the question related to prenatal testing. A data list of verbatim participant responses was provided separately for both groups, with data labeled for each individual participant. To compare across the two groups, the data records were analyzed according to the prenatal and postnatal grouping of data for the analysis process.

Data analysis and reporting were conducted using multiple coders and team consensus. The use of this type of investigator triangulation (Patton, 2002) strengthened the verification and validity of the content analysis by minimizing the potential for bias that can arise from a single analyst. The team consisted of one of the first co-authors (B.N.G.) as a faculty primary investigator (PI) and three undergraduate research assistants. The individual team members independently conducted content analysis of the qualitative data records and identified patterns within the data. The team met 2-3 times per month to review their identified codes and develop consensus regarding the coding of the data. The PI compiled a codebook and the team reviewed the data and codes to reach consensus. Once team consensus was reached regarding the data record codes, the group organized the data according to the identified categories to assess for their substantive significance (Patton, 2002). Substantive significance is the method by which qualitative findings are evaluated for scientific merit, similar to that of statistical significance for quantitative data (Patton, 2002). To conclude the analysis, the group identified the strongest of the categories, based on breadth and depth, and identified participant quotes that particularly captured the essence of each category to serve as exemplars (Patton, 2002). Thus, substantive significance was determined through the use of several methods of triangulation (e.g., multiple coders and team consensus), constant comparison analysis, repeated reviewing of the data, and cross comparison of the consensual code validation by all team members.

In the current study, eight total categories were identified, which were regularly revised and updated throughout the analysis process. Several categories included descriptive subcategories and the data analysis included both prenatal and postnatal groups for each category. The eight preliminary categories included: prenatal testing decisions/experiences, medical professionals, previous interactions/experiences with DS/disabilities, resources/support for parents, parents' adjustment process, the birth experience, parents' relationship, and a category for other/miscellaneous. The final results described here consisted of the three most frequently identified and most salient categories, based on individual member coding and group consensus.

\section{Results}

Participants were divided into prenatal $(n=46)$ and postnatal $(n=115)$ diagnosis groups, based on how they learned of their child's diagnosis, either during pregnancy or after their child's birth, respectively. Summary demographic data for the sample are provided in Table 1.

Data from the qualitative interviews were analyzed for common categories. In the current study, three primary categories resulted: prenatal screening/testing decisions by parents, the adjustment process for parents, and postdiagnosis resources and support for parents. Primary themes and subthemes will be described below, including the total number of the participants who described each theme and subtheme, supporting quotes, and participant group and code numbers for selected exemplar quotes. A summary of the qualitative data is provided in Table 2 .

\section{Prenatal Screening/Testing Decisions by Parents}

One of the primary points for understanding the initial of experiences parents of children with DS involves their choices related to prenatal screening and testing. To fully address this question, the study 
Table 1

Summary of Demographic Statistics

\begin{tabular}{lcc}
\hline & Prenatal group $(n=46)$ & Postnatal group $(n=115)$ \\
\hline Gender & & \\
Male & $6.5 \%(n=3)$ & $10.4 \%(n=12)$ \\
Female & $93.5 \%(n=43)$ & $89.6 \%(n=103)$ \\
Mean age (years) & $40.2(S D=6.89)$ & $41.43(S D=8.45)$ \\
Ethnicity: European American & $87.0 \%(n=40)$ & $87.8 \%(n=101)$ \\
Marital status: & & \\
$\quad$ Currently married & $84.8 \%(n=39)$ & $87.4 \%(n=97)$ \\
$\quad$ Mean relationship length & $11.85(S D=6.75)$ & $13.35(S D=9.00)^{*}$ \\
Education level: & & \\
$\quad$ Some college & $37.0 \%(n=17)$ & $24.3 \%(n=28)$ \\
College degree & $28.3 \%(n=13)$ & $35.7 \%(n=41)$ \\
Annual income over $\$ 80,000$ & $55.6 \%(n=25)$ & $63.9 \%(n=72)$ \\
Children with DS: & & \\
Male & $52.2 \%(n=24)$ & $56.5 \%(n=65)$ \\
Female & $44.8 \%(n=22)$ & $74.6 \%(n=51)$ \\
Mean age (years) & $4.84(S D=4.45)$ & $(S D=8.13)^{* * * *}$ \\
\hline
\end{tabular}

${ }^{*} F=4.89, p<.05 ; * * * F=14.25, p<.001$.

participants were divided into two groups: those who participated in prenatal testing $(n=46)$ and those who did not participate in prenatal testing (postnatal group; $n=115$ ). Within each of these groups there are several reasons for parents making their decision, as well as, whether or not they would make the same decision again.

In the prenatal group, $67 \%$ of participants $(n=$ 31) said they would make the same decision to have prenatal testing with future pregnancies. Of these,

Table 2

Qualitative Data by Group

$$
\text { Prenatal group }(n=46) \quad \text { Postnatal group }(n=115)
$$

PNS/T

Same decision

Negative PNS results

Would do PNS/T in future

Adjustment process

Short

Other medical problems

Resources/Support

Neg. medical professional

Pos. medical professional

Pos. other resource/support

Neg. other resource/support

Faith/religion
$67 \%(n=31)$

$35 \%(n=40)$

$39 \%(n=45)$

$13 \%(n=15)$

$$
15 \%(n=7)
$$$$
26 \%(n=30)
$$

$26 \%(n=12)$

$23 \%(n=26)$

$$
\begin{aligned}
35 \%(n & =16) \\
11 \%(n & =5) \\
48 \%(n & =22) \\
9 \%(n & =4) \\
17 \%(n & =8)
\end{aligned}
$$

Note. PNS/T $=$ prenatal screening/testing; Neg. $=$ negative experience; Pos. $=$ positive experience. 
21 participants cited preliminary screening results or medical problems identified in a screening as their reason for participating in prenatal testing. Other reasons for choosing prenatal testing included: maternal age $(n=7)$, to be better prepared $(n=4)$, and because of previous pregnancies with abnormalities $(n=1)$. One participant stated, "Looking back, I am glad that we did prenatal testing just so that we could be prepared and knowledgeable before our son was born. It made delivery day a happy day - and not one that was tainted with a diagnosis" (Prenatal \#15).

In the postnatal group, $35 \%(n=40)$ of participants reported not having prenatal screening and indicated they would not to do so in the future, $39 \%(n=45)$ reported that they had a negative prenatal screening or did not have full testing, and $13 \%(n=15)$ did not have prenatal testing but expressed that they would in the future. The reasons for not participating in prenatal testing included: avoiding worry and stress $(n=13)$, the risks involved with testing $(n=10)$, it would not affect the decision to terminate the pregnancy $(n=$ $19)$, young age $(n=6)$, testing was not available ( $n$ $=3)$, previous healthy pregnancies $(n=3)$, lack of knowledge concerning pregnancy risks $(n=1)$, and religious beliefs $(n=1)$. In regards to her decision to not do prenatal testing at the time of the pregnancy or future pregnancies, one participant stated, "I liked the idea that there wasn't a black cloud hanging over me during my pregnancy" (Postnatal \#19). The 15 prenatal group participants who indicated they would complete prenatal testing in the future reported various reasons, including: to be better prepared $(n=3)$, their spouse desires testing $(n=3)$, to know if their child would have DS before birth $(n=2)$, to have at least partial testing $(n=2)$, required by medical professionals $(n=1)$, to avoid worrying about problems in the future $(n=1)$, to have access to resources during pregnancy $(n=1)$, to avoid the surprise $(n=1)$, and to not have additional children with special needs $(n=1)$. One participant who indicated they would do prenatal testing in the future stated, "He [her son] and his gentle disability have gently walked us through acceptance, one phase after another, and we have been grateful for that considerate acceptance process. Given the choice now, we would choose testing to get the proper professionals on hand to support the birth and prepare for early intervention" (Postnatal \#86).
While the decision for choosing whether to have prenatal testing varies from participant to participant, several reasons were identified as recurring themes in the participant data. Often the initial experience with prenatal testing influenced the desire of participants to choose prenatal testing with future pregnancies. The experiences of the participants were varied and demonstrate the necessity for a greater understanding of their initial experiences.

\section{Adjustment Process for Parents}

Initial reactions. Another primary theme identified in the data involved the parents' adjustment to the DS diagnosis. Overall, the majority of the participants, regardless of whether they had prenatal testing or learned of the diagnosis after the birth, indicated that their initial reactions to learning that their child had DS were those of grief, fear, mourning, overwhelmed, denial, guilt, anger... almost every human emotion. Parents described it as: "having every emotion there all at one time," "the full range of emotions," and "a complete rollercoaster of emotions." Several parents in the prenatal testing group $(n=9)$ specifically reported feeling "devastation and shock" upon learning about the probability of DS. Grief was reported as a primary reaction to the diagnosis in both groups. Grief and devastation generally came from feelings of loss in relation to the image that parents had of their future child and the vision of the future of their family. Parents described having to go through the process of "mourning the loss of their baby." For many parents, the grief sourced from thoughts, such as:

"I saw all the dreams for my son disappear." (Prenatal \#13)

"We cried until there were no more tears. All we could think was that it was somehow our fault and that his future would be so difficult. That our perfect baby we dreamed of was now far from that image we had." (Postnatal \#26)

"I thought everything we had planned in life was over... I couldn't help but think that our daughter would probably never win a spelling bee, be asked to prom, be able to get her driver's license, attend college, or possibly never move away from home." (Prenatal \#30)

A source of these initial negative reactions many parents reported when learning about the diagnosis was related to fear of "what the future would hold for us and our daughter" (Prenatal \#11). Other sources of fear for parents in both groups came from the lack of knowledge as a 
parent, of what to expect of their child, and fear of the unknown about their child's or family's future.

Shock and anger also were predominant reactions reported by respondents. The adjustment of having to change the image parents had of their future child was an unexpected challenge, causing shock for many parents. Anger sometimes was expressed in the question of "Why me?" and one parent expressed that she "would get angry at any parent who has a typically developing child" (Prenatal \#7).

Although shock, fear, and grief were reported by most parents as their preliminary reactions, whether they learned of the diagnosis before or after the birth, a few parents reported more positive initial reactions, like feeling that their child was a gift and blessing (Prenatal \#1 and \#9), or feeling a sense of relief or peace and immediate acceptance at the diagnosis (Postnatal \#7 and \#50). Parents typically described that once their child was born, their adjustment to the idea of having a child with DS progressed greatly towards acceptance and celebration. "Those fears continued until minutes after I delivered her. I stared at her in awe and realized she was perfect. I felt a sense of calm at that point" (Prenatal \#6).

The knowledge of having a child with DS before the child arrives had mixed effects on parents in relation to their adjustment, but for the most part the parents that had prenatal knowledge of the DS diagnosis believed it was a positive experience because they could prepare for when the child arrived. One parent said that knowing about her child's DS simply caused her more worry during her pregnancy. Meanwhile, another parent stated that knowing about her child's DS before her daughter was born allowed her to "go through all of the emotions and loss before my child was born. When she arrived I was ready to be a mom without all of the negative feelings" (Prenatal \#3).

While these were not the most common initial reactions reported by parents, it is important to note that not every parent responds with negative emotions or reactions to the news of their child's diagnosis. In general, parents in both groups described their initial emotional response to the diagnosis as negative but gradually they came to experience more positive emotions and acceptance in their process of adjustment.

Process of adjustment. The "process of adjustment" to the diagnosis was another area described by the participants. Parents in both groups varied in the time it took to adjust to the news, from almost immediately after the diagnosis to several months, with a few indicating several years in their adjustment. However, more postnatal $(26 \% ; n=30)$ group participants compared to prenatal group participants $(15 \% ; n=7)$ indicated that they had a fairly short adjustment time or had to adjust fairly quickly to the DS diagnosis. "While we were in the NICU, I realized then that things could have been far worse and I began to realize that I had a baby much like any other" (Postnatal \#45); "I can honestly say my initial reaction to finding out we had a child with Down syndrome was 'So what?"' (Postnatal \#80). A few parents in both groups $(n=5$, prenatal; $n=9$, postnatal) reported that they had a very long adjustment process. One parent stated, "It's been over two years and I am still adjusting" (Prenatal \#55).

A primary factor that contributed to the adjustment process involved the adjustment to the DS diagnosis when other medical problems were the primary focus. Participants in both the prenatal $(26 \% ; n=12)$ and postnatal $(23 \% ; n=$ 26) groups reported that their child also had other medical issues, usually heart problems. When DS was put into perspective with medical difficulties that could be terminal, it helped parents realize that DS was something that they could deal with because it did not mean that their child was going to die. "The diagnosis of partial AV canal put our daughter's DS diagnosis into better perspective immediately for us. She might walk, talk and read later than most kids, but our primary concern would be to keep her healthy and enjoy the gift of her life" (Prenatal \#25). Another parent stated, "Mainly the process in adjusting involved navigating all of the medical concerns-I wasn't aware that a developmental disability could be accompanied by so many serious medical issues right away" (Postnatal \#31).

Overall, parents described the full breadth of emotions during their initial phase of learning about the diagnosis of DS, followed by a process of adjustment and coping. In addition, several participants described various resources and support that were significant in that adjustment process.

\section{Postdiagnosis Resources and Support for Parents}

Once parents navigated through the initial adjustment, they reported several sources and potential 
resources that influenced their adjustment to the DS diagnosis. Some of these experiences were perceived by the parents as positive or supportive resources, while others were detrimental or negative experiences. The resources and support expressed by the participants in the survey are organized into three primary areas: experiences with medical professionals, information/education and sources of support, and faith/religion.

Experiences with medical professionals. Although participants were not directly asked to describe their experiences with medical professionals, this was a primary theme reported by the participants. Participants in both groups reported both negative and positive experiences with their medical professionals; however, the negative experiences outnumber positive experiences 2.5 to 1 . In the prenatal group, $35 \%(n=16)$ indicated negative experiences. The reasons for the negative perceptions included: the medical professionals' insistence on terminating the pregnancies $(n=11)$, the perpetuation of negative stereotypes of individuals with DS $(n=7)$, the lack of information about DS provided by the medical professionals $(n=5)$, and the perceived lack of compassion exhibited by the medical professionals $(n=4)$.

As with the prenatal groups, many participants in the postnatal group reported negative experiences $(24 \% ; n=27)$ with their medical professionals. The participants reported the reasons their experiences were perceived as more negative included: the lack of compassion when explaining the diagnosis $(n=17)$, pressure to have prenatal testing $(n=4)$, the lack of information provided or perceiving that their doctor was not educated about DS $(n=3)$, the lack of support and low expectations for their children $(n=3)$, and because the medical professionals did not tell the parents the diagnosis at the time of birth $(n=2)$.

Fewer participants in both groups reported positive experiences with medical professionals. In the prenatal group, $11 \%(n=5)$ of participants described positive experiences with medical professionals; two participants expressed their experience as positive because the professionals discussed other options besides termination of the pregnancy, and one participant described how the medical professionals provided resources immediately after the diagnosis. There were also few positive experiences reported by the postnatal group $(4 \%, n=5)$; one participant described her experience: "A good friend who is an [obstetrician] delivered my baby.
She told me she was beautiful, and she was perfect, and she was quite sure she had Down syndrome" (Participant \#39). Others indicated that the nurses were very supportive emotionally or that they were given information and resources by the medical professionals. Thus, the current results indicated that most participants reported their initial experiences with medical professionals were primarily negative, which has important implications for the disability and medical communities.

Seeking information, education and support. A second area that was reported by participants in both groups involved seeking information/education about DS and seeking support to cope with the diagnosis. Participants in both groups reported actively seeking information about DS as a resource. Almost half $(48 \% ; n=22)$ of the prenatal group participants reported positive experiences, including feeling more prepared after reading information $(n=13)$, finding parent support groups and other DS organizations $(n=$ $9)$, meeting with medical specialists $(n=8)$, meeting other parents of children with DS $(n=$ 7 ), and seeking support from family and friends ( $n$ $=4$ ). One participant shared how research affected her reaction: "I realized I didn't know enough about the condition and that all of preconceptions were wrong. I began to feel hopeful about my baby's possible future" (Prenatal \#10).

Similarly, about half of the postnatal group participants reported seeking information/education as a resource. Of these, $48 \%(n=55)$ viewed this as a positive experience, and included a variety of sources: researching or reading about DS $(n=$ 25 ), finding parent support groups and DS organizations $(n=17)$, seeking support from family and friends $(n=16)$, talking with other parents of children with DS $(n=11)$, receiving early intervention or other services $(n=10)$, meeting with medical specialists to learn more about their child's diagnosis $(n=7)$, and receiving support from their spouse $(n=4)$ were instrumental in their adjustment to their child's diagnosis.

It appeared that all of these methods of research were helpful to parents, but that meeting with parents who already had children with DS had a greater impact on moving the adjustment period along faster, as one parent stated: "Talking to parents of kids with DS and meeting beautiful children with DS helped us to be comforted that our son would be just like any other child" (Prenatal \#15). Another parent stated: 
"The most positive thing I did was meet with another parent of toddlers (twins) with Down Syndrome. After meeting them I knew I would be able to make this work and thought it would be hard but would figure things out." (Prenatal \#38)

A few participants in both groups reported negative experiences when seeking information or outside support. Both prenatal $(9 \%, n=4)$ and postnatal $(10 \%, n=12)$ participants reported having a negative experience. The prenatal group participants reported these experienced were due to frightening $(n=2)$ or outdated $(n=1)$ information or they experienced negative reactions from their family and friends $(n=1)$. In the postnatal group, some participants found that researching information was "overwhelming" and/ or "depressing" $(n=5)$, lacked support from family and friends $(n=4)$, had outdated information $(n=$ 2 ), or described how the support groups were focused on "mourning" rather than celebrating their children $(n=3)$. Overall, it appears that resources are integral in aiding new parents' adjustment to their child's diagnosis of DS. While there were some negative experiences with information/education and support, most participants who indicated a negative experience also stated positive aspects of these resources.

Faith/religion as a resource. Finally, the role of faith/religion was reported as a valuable resource for some participants. Approximately $17 \%(n=8)$ of prenatal group participants described how faith/ religion played a role in their adjustment to their child's diagnosis, discussing their personal faith in their response or reporting a church-based support group. For the participants who found out the diagnosis after birth, faith/religion played a role for $20 \%(n=23)$ of participants in their adjustment; they stated that their personal faith was a large part of their adjustment and describing their child as a "blessing" or "gift" from a higher power. One parent shared, "She [daughter with DS] is a blessing, each and every day we get to be her parents" (Postnatal \#25). Faith played a large role in many of respondents' process of adjustment; for some couples it was their "faith in God that He would give us the grace to deal with the medical, physical, cognitive and social challenges-and $\mathrm{He}$ has!” (Prenatal \#20).

\section{Discussion}

The current study explored the experiences of parents of children with DS, specifically addressing their initial experiences of learning about and adjusting to their child's diagnosis. A national sample of parents participated in the online survey and data were analyzed to determine whether there were differences in experiences for parents who received a prenatal or postnatal diagnosis. While there is some literature that addresses the stress experienced by parents with a child with a disability, to our knowledge, specifically comparing prenatal and postnatal groups has not directly been assessed. In the current study, these two groups were "more alike than different" (Bower et al., 1998; NDSC, 2011) in their preliminary experiences and process of adjustment to the DS diagnosis and accessing resources and sources of support. While the primary difference between the groups was the timing of when they learned of their child's diagnosis, participants in both groups indicated they would make the same testing decision in the future.

It is clear from the research that parents have unique reasons for their prenatal testing decisions. Those participants who did not pursue prenatal screening or testing procedures made references that test results "would not change" their decision to proceed with the pregnancy. In contrast, those who chose prenatal testing in this sample identified the importance of "preparing" for the future in caring for their child and becoming more informed about DS. In light of the termination rate of pregnancies linked to DS, it is necessary to recognize that prenatal testing is not always for the purpose of termination and to be cautious in making such an assumption (Skotko, 2012). The results of this study identified various reasons why parents make their prenatal screening/testing decisions, confirming that each would make the same decisions in the future. Only 13\% of the postnatal group participants indicated they would pursue prenatal screening in future pregnancies.

While the specific results from both groups did not necessarily result in differences between these two groups of parents, the results provided an empirical understanding of these early experiences of parents by providing a description of primary areas reported by the participants. Others have described this preliminary experience as a "flashbulb memory" (Skotko, 2005), one that parents do not forget and that is etched in their memories forever. The current study results would concur; while some of the parents' experiences were years 
earlier, their descriptions of that first experience of learning about their child's DS diagnosis was as clear as if it had just happened, their descriptions laden with emotions and very specific details of their memories of that moment. Parents in both groups described the overwhelming emotions, including grief, loss, mourning, guilt, and anger, that they experienced. Other research has described similar reports from parents (Joosa \& Berthelsen, 2006; Poehlman et al., 2005). We were curious whether there was more grief, anger, or more positive reactions reported by one group compared to the other, but it was clear from the results that the emotions were very similar, regardless of when the diagnosis was delivered. However, similar to other research (Skotko, Capone, et al., 2009; Skotko, Kishnani, et al., 2009), how that diagnosis was delivered resulted in a very clear theme described by parents in both groups, most describing negative experiences with medical professionals. Although this was not a direct question in the online survey, the prenatal group reported slightly more negative experiences (35\%) compared with the postnatal group (24\%) and the differences involved primarily pressure to terminate the pregnancy for the prenatal group. Both groups reported a lack of accurate and current information about DS and little to no compassion or support from the medical professionals with whom they interacted. While this might be expected 15-20 years ago, based on the children's ages, these parents were reporting on very recent experiences, some occurring within the past 1-2 years. This finding has critical implications for professional development that will be described later.

Participants in both groups actively sought information about DS after the diagnosis, pursued support from other parents or other resources during the process of adjustment, and described the importance their faith/religion played in coping. In addition, while most parents initially reported a negative reaction to the diagnosis, they also described it as a "process of adjustment" and one that eventually they began to experience more positively. For some, the seriousness of their child's medical problems (e.g., heart problems or other life-threatening issues) became their primary concern for both prenatal and postnatal participants, overriding their concerns about the DS diagnosis.

\section{Study Limitations}

The current research provided information on the preliminary experiences of parents facing the initial diagnosis of DS in their child. The sample of the study was relatively large for qualitative research and represented participants from across the United States, including both male and female participants. In addition, the study explored both similarities and differences between parents who had received the diagnosis prenatally and those who were informed after their child was born. Although the current sample included a national sample, participants were predominantly White, married women who reported a high socioeconomic status. While the sample size was unique for qualitative research and generated a large data set, there was only one question that was analyzed from the online survey data for the current study. The current study was part of a larger study exploring the positive aspects of parenting a child with DS, which should glean additional results to further understand parents' varied experiences. Finally, the presence of "complex needs" in this sample of children with DS was not assessed in the current study, so severity of impairment or multiple diagnoses (e.g., autism and DS, severe medical or behavioral issues) in the sample was unknown.

\section{Future Research and Practice Implications}

There are a number of areas that require further exploration in the research. We concur with Cuskelly et al. (2009) that there is a need to acknowledge both positive and negative aspects of family members' experiences with DS and other disabilities, including the early experiences but also addressing longitudinal studies over time and at all age levels. In addition to the limitations noted previously, further research is needed to explore the experiences of fathers of children with DS (Bentley, 2011) and more diverse and representative populations (Cuskelly et al., 2009; Hodapp, 2007).

In addition to the research implications, the current results also provided several practice implications for working with parents of children with DS and other special needs. Foremost, it is critical that medical professionals provide accurate and current information to parents facing a difficult diagnosis in a supportive and compassionate manner (Skotko, 2005). The way the diagnosis is provided to the parents and how they are (or are 
not) supported by medical professionals seems to be as important as the diagnosis itself. These early contacts may be particularly important for new parents to get resources specific to DS in the local community, like parent support groups, or other national resources that can provide information and support to parents (e.g., NDSC, NDSS, online resources).

New parents of children with DS should be provided with specific and practical information that target their specific needs (e.g., medical issues) and referrals for additional specialized care and medical services. Navigating the plethora of information, which can be overwhelming to new parents, and identifying sources of support and encouragement is critical in adjusting to the news of their child's diagnosis and starting on the positive path necessary for positive parent and child outcomes. Parents need to be reassured that the intense range of emotions they feel is normal, but the new path they are on can have positive and rewarding outcomes.

\section{References}

Allen, J., \& Mulhauser, L. (1995). Genetic counseling after abnormal prenatal diagnosis: Facilitating coping in families who continue their pregnancies. Journal of Genetic Counseling, 4(4), 251-265. doi: 10.1007/BF01408072

Bower, A., Chant, D., \& Chatwin, S. (1998). Hardiness in families with and without a child with Down syndrome. Down Syndrome Research and Practice, 5(2), 71-77. doi: 10. 1007/BF01408072

Creswell, J. W., Hanson, W., Plano Clark, V., \& Morales, A. (2007). Qualitative research designs: Selection and implementation. The Counseling Psychologist, 35(2), 236-264. doi: 10.1177/0011000006287390

Cunningham, C. (1996). Families of children with Down syndrome. Down Syndrome Research and Practice, 4(3), 87-95. doi:10.3104/perspectives. 66

Cuskelly, M., Hauser-Cram, P., \& Van Riper, M. (2009). Families of children with Down syndrome: What we know and what we need to know. Down Syndrome Research 83 Practice, 12(3), 202-210. doi:10.3104/reviews/2079

Flaherty, E., \& Masters Glidden, L. (2000). Positive adjustment in parents rearing children with
Down syndrome. Early Education and Development, 11(4), 407-422.doi: 10.1207/s15566935eed1104_3

Glidden, L. M., Billings, F. J., \& Jobe, B. M. (2006). Personality, coping style and well-being of parents rearing children with developmental disabilities. Journal of Intellectual Disability Research, 50(12), 949-962. doi: 10.1111/j. 1365-2788.2006.00929.x

Grant, G., Ramcharan, P., \& Flynn, M. (2007). Resilience in families with children and adult members with intellectual disabilities: Tracing elements of a psycho-social model. Journal of Applied Research in Intellectual Disabilities, 20, 563-575. doi: 10.1111/j.1468-3148.2007.00407.x

Hodapp, R. M. (2007). Families of persons with Down syndrome: New perspectives, findings, and research and service needs. Mental Retardation and Developmental Disabilities Research Reviews, 13(3), 279-287. doi:10.1002/mrdd. 20160

Humphreys, L., Cappelli, M., Aronovitch, E., Allanson, J., \& Hunter, A. (2008). The role of women's relationships with their partners in their adjustment following prenatal genetic testing. Journal of Applied Social Psychology, 38(2), 482-512. doi: 10.1111/j.1559-1816. 2007.00314.x

Joosa, E., \& Berthelsen, D. (2006). Parenting a child with Down syndrome: A phenomenographic study. Journal on Developmental Disabilities, 12(1S2), 45-58.

King, G., Baxter, D., Rosenbaum, P., Zwaigenbaum, L., \& Bates, A. (2009). Belief systems of families of children with autism spectrum disorders or Down syndrome. Focus on Autism and Other Developmental Disabilities, 24(1), 50 64. doi:10.1177/1088357608329173

McCubbin, H. I., \& Thompson, A. I. (Eds.) (1991). Family assessment inventories for research and practice. Madison, WI: University of Wisconsin.

National Down Syndrome Congress. (2012, March 6). Informational resources-Expectant Parent [Web information page]. Retrieved from http://www.ndsccenter.org/?page_id $=1525$

Patton, M. Q. (2002). Qualitative research and evaluation methods, $3^{\text {rd }}$ ed. Thousand Oaks, CA: Sage.

Poehlmann, J., Clements, M., Abbeduto, L., \& Farsad, V. (2005). Family experiences associated with a child's diagnosis of Fragile X or Down syndrome: Evidence for disruption and resilience. Mental 
Retardation, 43(4), 255-267. doi:10.1352/00476765(2005)43[255:FEAWAC]2.0.CO;2

Sandelowski, M., \& Barroso, J. (2005). The travesty of choosing after positive prenatal diagnosis. Journal of Obstetric, Gynecologic, and Neonatal Nursing, 34(3), 307-318. doi: 10.1177/ 0884217505276291

Sandelowski, M., \& Jones, L. (1996). 'Healing fictions': Stories of choosing in the aftermath of the detection of fetal anomalies. Social Science Medicine, 42(3), 353-361. doi: 10.1016/ 0277-9536(95)00102-6

Skotko, B. (2005). Mothers of children with Down syndrome reflect on their postnatal support. Pediatrics, 115, 64-77. doi: 10.1542/peds.20040928

Skotko, B. (2012, May 27). What exactly is the termination rate for babies with Down syndrome? [Online forum comment]. Retrieved from http:// www.idscforlife.org/2012/05/what-exactly-istermination-rate-for.html

Skotko, B. G., Capone, G. T., Kishnani, P. S., \& Down Syndrome Diagnosis Study Group. (2009). Postnatal diagnosis of Down syndrome: Synthesis of the evidence on how best to deliver the news. Pediatrics, 124(4), e751-e758. doi:10.1542/peds.2009-0480

Skotko, B. G., Kishnani, P. S., Capone, G. T., \& Down Syndrome Diagnosis Study Group. (2009). Prenatal diagnosis of Down syndrome: How best to deliver the news. American Journal of Medical Genetics, 149A, 2361-2367. doi: 10.1002/ajmg.a.33082
Twoy, R., Connolly, P. M., \& Novak, J. M. (2007). Coping strategies used by parents of children with autism. Journal of the American Academy of Nurse Practitioner, 19, 251-260. doi: 10.1111/ j.1745-7599.2007.00222.x

Van Hooste, A., \& Maes, B. (2003). Family factors in the early development of children with Down syndrome. Journal of Early Intervention, 25(4), 296-309. doi:10.1177/105381510302500405

Van Riper, M. (2007). Families of children with Down syndrome: Responding to 'a change in plans' with resilience. Journal of Pediatric Nursing, 22(2), 116-128. doi: 10.1016/j.pedn. 2006.07.004

Received 8/28/2012, first decision 11/15/2012, second decision 5/16/2013, accepted 5/31/2013.

Editor-in-charge: Glenn Fujiura

\section{Authors:}

Briana S. Nelson Goff, PhD, Professor, School of Family Studies and Human Services, Kansas State University, 343K Justin Hall, Manhattan, KS 665061403; bnelson@k-state.edu; Nicole Springer, Gail E. Bentley, and Kayli A. Cross, Texas Tech University; Laura Cline Foote, Courtney Frantz, Madison Peak, Courtney Tracy, and Taylor Veh, Kansas State University. 


\section{Résumés en Français}

Recevoir le diagnostic initial du syndrome de Down: une comparaison des expériences des groupes de parents prénatal et postnatal

\section{Briana S. Nelson Goff, Nicole Springer, Laura Cline Foote, Courtney Frantz, Madison Peak, Courtney Tracy, Taylor Veh, Gail E. Bentley, Kayli A. Cross}

Cette étude explore les expériences préliminaires de parents recevant l'annonce du diagnostic du syndrome de Down pour leur enfant. Des données qualitatives provenant d'une base de données électronique d'un sondage national ont été analysées en se basant sur deux groupes : diagnostic prénatal $(n=46)$ ou postnatal $(n=115)$. Trois catégories primaires ont été identifiées à partir de l'analyse des données : dépistage prénatal/décision d'évaluation par les parents, le processus d'ajustement pour les parents, et les ressources et le soutien disponibles aux parents à la suite du diagnostic. Le raisonnement des participants pour la poursuite de l'évaluation allait de vouloir être mieux préparés à ne pas poursuivre l'évaluation parce que ce n'était pas un facteur pour continuer la grossesse. Les réactions des participants à l'annonce du diagnostic étaient un éventail d'émotions préliminaires intenses : les participants décrivaient leur deuil extrême et leur expérience de perte à l'annonce initiale du diagnostic, qui était ambigüe de nature et qui requerrait un ajustement en plusieurs temps. Finalement, les participants ont décrit leur expérience avec les professionnels médicaux, l'information et l'éducation, les croyances et religion, comme des ressources de soutien, bien qu'elles ne soient pas toutes décrites comme positives. Les participants des deux groupes ont rapporté avoir vécu des expériences négatives avec les professionnels médicaux durant le processus diagnostique. Les résultats indiquent l'importance des premières expériences pour les parents d'enfants ayant un syndrome de Down et mettent de l'avant les besoins d'éducation efficace, de ressources, et d'informations pratiques provenant de sources fiables.

Les politiques et pratiques d'état dans le soutien comportemental pour les personnes ayant une déficience intellectuelle aux États-Unis: une enquête nationale

\author{
David A. Rotholz, Charles R. Moseley, \\ et Kinsey B. Carlson
}

Donner un soutien comportemental efficace pour diminuer les troubles du comportement et les remplacer par des habiletés alternatives plus appropriées est essentiel pour répondre aux besoins de plusieurs personnes ayant une déficience intellectuelle (DI). Il est aussi nécessaire afin de répondre aux conditions du plan de soutien individualisé Medicaid, et il est important pour des raisons morales, éthiques et sociales. Malheureusement, il n'y a pas de standard national pour les pratiques de soutien comportemental ou une source d'informations sur le statut des politiques de soutien comportemental, les pratiques, et les services pour les adultes ayant une DI sur le plan des états ou national. La collecte de données sur l'état de la définition du soutien comportemental par état, les qualifications des fournisseurs, la formation, et les conditions de surveillance sont un point de départ nécessaire pour le développement de plans qui prennent en compte changer les politiques et les pratiques. Cette enquête est la première évaluation nationale des politiques et pratiques d'état concernant la définition et l'offre de services pour le soutien comportemental aux personnes ayant une DI et recevant un soutien financé publiquement aux États-Unis.

L'efficacité de l'enseignement répondant avec les enfants ayant un syndrome de Down

\section{Ozcan Karaaslan et Gerald Mahoney}

Une étude aléatoire a été effectuée pour évaluer l'enseignement répondant (ER) avec un échantillon composé de 15 enfants turcs d'âge préscolaire et ayant un syndrome de Down ainsi que leur mère sur une période de six mois. L'ER est un procédé d'interventions précoces qui tentent de promouvoir le développement de l'enfant en encourageant les interactions très réactives des parents envers leurs enfants. Les participants ont été attribués aux conditions de traitement de manière aléatoire : le groupe contrôle consistait en des classes de préscolaires régulières, le groupe ER participait à des séances ER parent-enfant deux fois par semaine en plus de recevoir les services réguliers. Les mères 
Reproduced with permission of the copyright owner. Further reproduction prohibited without permission. 